\title{
Safety and Efficacy of Flexible Ureterorenoscopy Surgery in Different Age Groups
}

\author{
Omer Koras ${ }^{1}$, Ibrahim Halil Bozkurt ${ }^{2}$, Ahmet Nihat Karakoyunlư ${ }^{3}$, Salih Polat ${ }^{4}$, Serkan Yarimoglu ${ }^{2}$ and Tansu \\ Degirmenci \\ ${ }^{1}$ Department of Urology, Faculty of Medicine, Mustafa Kemal University, Antakya/Hatay, Turkey \\ ${ }^{2}$ Department of Urology, HSU Izmir Bozyaka Training and Research Hospital, Izmir, Turkey \\ ${ }^{3}$ Department of Urology, HSU Ankara Diskapi Training and Research Hospital, Ankara, Turkey \\ ${ }^{4}$ Department of Urology, Faculty of Medicine, Amasya Universty, Şerefeddin Sabuncuoğlu Training and Research Hospital, \\ Amasya,Turkey
}

\begin{abstract}
Objective: To comparatively investigate the efficacy, safety and complications of flexible ureterorenoscopy (f-URS) in the treatment of patients of different age groups ( $<60,60-74$ and $\geq 75$ years) with proximal ureteral and kidney stones.

Study Design: Descriptive study.

Place and Duration of Study: Department of Urology, HSU Izmir Bozyaka Training and Research Hospital, HSU Ankara Diskapi Training, Research Hospital, and Mustafa Kemal University Faculty of Medicine, between March 2014 and June 2020.

Methodology: Nine hundred and fifty-six patients, who underwent f-URS due to proximal ureteral and kidney stones, were divided into three age groups as $<60$ years (Group 1), 60-74 years (Group 2) and $\geq 75$ year (Group 3). The patients' American Society of Anesthesiologists (ASA) score, Charlson Comorbidity Index (CCI), anticoagulant use, stone-free rates and surgical and medical complication rates were examined for each group.

Results: There were 688 patients in Group 1, 230 in Group 2, and 38 in Group 3. A significant difference was observed between the age groups in terms of $\mathrm{CCl}$ and anticoagulant use $(p<0.001$ for both). The highest rate of medical complications was observed in Group 3 at $42.1 \%$, followed by Group 2 at 17.8\%, while the lowest rate was observed in Group 1 at $2.3 \%$ $(p<0.001)$. As a result of the multivariate analysis, receiving anticoagulant treatment $(p=0.002)$ and having a high $\mathrm{CCl}$ $(p=0.005)$ were independent predictors of medical complication development.

Conclusion: It was clearly demonstrated that f-URS could be used as a safe and effective alternative for the treatment of moderate-size kidney stones in all age groups.
\end{abstract}

Key Words: Elderly, Geriatric patients, RIRS, Holmium laser lithotripsy, Urolithiasis, Safety, Efficacy.

How to cite this article: Koras O, Bozkurt IH, Karakoyunlu AN, Polat S, Yarimoglu S, Degirmenci T. Safety and Efficacy of Flexible Ureterorenoscopy Surgery in Different Age Groups. J Coll Physicians Surg Pak 2021; 31(06):679-685.

\section{INTRODUCTION}

Various studies have shown that the prevalence of kidney stones is increasing, and its incidence also rises with advancing age. ${ }^{1}$ The World Health Organization (WHO) defines individuals aged 65 years and older as the elderly. ${ }^{2}$ It is estimated that the population over the age of 60 years will exceed 2 billion over the next three decades, and stone disease will be more common in elderly patients, secondary to the increase in the incidence of kidney stones with the prolongation of life expectancy. ${ }^{3}$

Correspondence to: Dr. Omer Koras, Department of Urology, Faculty of Medicine, Mustafa Kemal University, Antakya/Hatay, Turkey

E-mail: korasdr@gmail.com

Received: March 08, 2021; Revised: April 28, 2021; Accepted: May 18, 2021

DOI: https://doi.org/10.29271/jcpsp.2021.06.679
There is still no standardisation for the surgical approach in elderly patients due to increasing comorbidities and surgical complications. Although aging itself is not a disease, it is feared that the decrease in functional organ reserve with aging may trigger complications in the perioperative and postoperative period. Therefore, it is very important to determine the surgical procedure to be performed in elderly patients.

Flexible ureterorenoscopy (f-URS), first performed in the $1990 \mathrm{~s},{ }^{4}$ has become the first option in the treatment of upper urinary tract stones smaller than $2 \mathrm{~cm}$, with the advances in flexible endoscopes, light and image quality, and stone breaking technologies. ${ }^{5}$-URS is a minimally invasive surgical procedure with a higher success rate than extracorporeal sound wave lithotripsy (ESWL) and less morbidity than percutaneous nephrolithotomy (PCNL) and open stone surgery. ${ }^{6}$ The treatment of upper urinary tract stones has changed in recent years due to low morbidity and high success rates. 
Table I: Patient and stone characteristics.

\begin{tabular}{|c|c|c|c|c|}
\hline Variables & $\begin{array}{l}\text { Group } 1 \\
(<60 \text { years) } \\
(n=688)\end{array}$ & $\begin{array}{l}\text { Group } 2 \\
(60-74 \text { years }) \\
(n=230)\end{array}$ & $\begin{array}{l}\text { Group } 3 \\
(\geq 75 \text { years) } \\
(\mathrm{n}=\mathbf{3 8})\end{array}$ & p-value \\
\hline Age, years, median (IQR) & $42(34-49)^{a}$ & $62(62-66)^{b}$ & $84(79-87.25)^{c}$ & $<0.001$ \\
\hline $\begin{array}{l}\text { Gender, } \mathrm{n}(\%) \\
\text { Female } \\
\text { Male }\end{array}$ & $\begin{array}{l}212(30.8)^{\mathrm{a}} \\
476(69.2)^{\mathrm{a}}\end{array}$ & $\begin{array}{l}117(50.9)^{b} \\
113(49.1)^{b}\end{array}$ & $\begin{array}{l}15(39.5)^{a, b} \\
23(60.5)^{a, b}\end{array}$ & $<0.001^{*}$ \\
\hline $\mathrm{BMI}, \mathrm{kg} / \mathrm{m}^{2}$ & $\begin{array}{l}26.4 \\
(24.0-29.1)^{a}\end{array}$ & $\begin{array}{l}28.5 \\
(26.0-32.4)^{b}\end{array}$ & $\begin{array}{l}27.0 \\
(23.0-29.4)^{\mathrm{a}}\end{array}$ & $<0.001$ \\
\hline Previous history of ESWL, $\mathrm{n}(\%)$ & $109(15.8)$ & $39(17.0)$ & $8(21.1)$ & 0.686 \\
\hline Metabolic syndrome, $\mathrm{n}(\%)$ & $55(8.0)^{a}$ & $64(27.8)^{b}$ & $27(71.1)^{c}$ & $<0.001$ \\
\hline $\begin{array}{l}\text { ASA category, } \mathrm{n}(\%) \\
\text { ASA I } \\
\text { ASA II } \\
\text { ASA III } \\
\text { ASA IV }\end{array}$ & $\begin{array}{l}374(54.4)^{\mathrm{a}} \\
281(40.8)^{\mathrm{a}} \\
33(4.8)^{\mathrm{a}} \\
0^{\mathrm{a}}\end{array}$ & $\begin{array}{l}31(13.5)^{\mathrm{b}} \\
137(59.6)^{\mathrm{b}} \\
57(24.8)^{\mathrm{b}} \\
5(2.2)^{\mathrm{b}}\end{array}$ & $\begin{array}{l}0^{c} \\
17(44.7)^{a, b} \\
15(39.5)^{b} \\
6(15.8)^{c}\end{array}$ & $<0.001^{\wedge}$ \\
\hline $\mathrm{CCl}$, score & $0(0-1)$ & $3(2-4)$ & $5(5-6)$ & $<0.001$ \\
\hline Anticoagulant therapy, n (\%) & $69(10.0)$ & $33(14.3)$ & $12(31.6)$ & $<0.001$ \\
\hline Abnormal renal anatomy, $\mathrm{n}(\%)$ & $42(6.1)$ & $22(9.6)$ & $5(13.2)$ & 0.075 \\
\hline $\begin{array}{l}\text { Side, } n(\%) \\
\text { Right } \\
\text { Left } \\
\text { Bilateral }\end{array}$ & $\begin{array}{l}343(49.9) \\
325(47.2) \\
20(2.9)\end{array}$ & $\begin{array}{l}99(43.0) \\
124(53.9) \\
7(3.0)\end{array}$ & $\begin{array}{l}15(39.5) \\
23(60.5) \\
0(0.0)\end{array}$ & 0.205 \\
\hline Sone location, n (\%) & & & & 0.228 \\
\hline $\begin{array}{l}\text { Lower calyx } \\
\text { Middle calyx } \\
\text { Upper calyx } \\
\text { Pelvis } \\
\text { Proximal ureteral } \\
\text { Multicaliceal } \\
\text { Kidney + ureteral } \\
\text { Pelvis + single calyx }\end{array}$ & $\begin{array}{l}126(18.3) \\
52(7.6) \\
41(6.0) \\
164(23.8) \\
136(19.8) \\
94(13.7) \\
49(7.1) \\
26(3.8) \\
\end{array}$ & $\begin{array}{l}58(25.2) \\
22(9.6) \\
6(2.6) \\
44(19.1) \\
39(17.0) \\
34(14.8) \\
17(7.4) \\
10(4.3) \\
\end{array}$ & $\begin{array}{l}8(21.1) \\
3(7.9) \\
1(2.6) \\
13(34.2) \\
3(7.9) \\
4(10.5) \\
4(10.5) \\
2(5.3)\end{array}$ & \\
\hline $\begin{array}{l}\text { Preoperative Hydronephrosis, n(\%) } \\
\text { Grade } 0 \\
\text { Grade } 1 \\
\text { Grade } 2 \\
\text { Grade } 3\end{array}$ & $\begin{array}{l}308(44.8) \\
310(45.1) \\
53(7.7) \\
17(2.5) \\
\end{array}$ & $\begin{array}{l}107(46.5) \\
92(40.0) \\
25(10.9) \\
6(2.6) \\
\end{array}$ & $\begin{array}{l}16(42.1) \\
15(39.5) \\
5(13.2) \\
2(5.3)\end{array}$ & 0.501 \\
\hline Stone length, $\mathrm{mm}$ & $13(10-20)$ & $14(10-20)$ & $15(10-20.5)$ & 0.104 \\
\hline Stone density, HU & $1033.5(864.2-1204)$ & $1023(858.5-1201)$ & $1015(854.2-1123.5)$ & 0.143 \\
\hline $\begin{array}{l}\text { Number of stones, } \mathrm{n}(\%) \\
\text { Single } \\
\text { Multiple }\end{array}$ & $\begin{array}{l}470(68.3) \\
218(31.7)\end{array}$ & $\begin{array}{l}157(68.3) \\
73(31.7)\end{array}$ & $\begin{array}{l}24(63.2) \\
14(36.8)\end{array}$ & 0.801 \\
\hline Preoperative stent, n (\%) & $111(16.1)$ & $52(22.6)$ & $5(13.2)$ & 0.063 \\
\hline \multicolumn{5}{|l|}{ Intraoperative characteristics } \\
\hline Operation time, min, median (IQR) & $45(35-60)$ & $49.5(38.75-65)$ & $50(45-70)$ & 0.068 \\
\hline Fluoroscopy time, sec, median (IQR) & $19(10-40)$ & $19(9-40)$ & $21(10-40.5)$ & 0.918 \\
\hline Use of ureteral access sheath, $\mathrm{n}(\%)$ & $524(76.2)$ & $175(76.1)$ & $30(78.9)$ & 0.924 \\
\hline Postoperative double-J stent placement, n(\%) & $628(91.3)$ & $220(95.7)$ & $38(100.0)$ & 0.018 \\
\hline
\end{tabular}

The aim of this study was to comparatively investigate the efficacy, safety and complications in patients of different age groups ( $<60$ years, $60-74$ years and $\geq 75$ years) who underwent $f$-URS for the treatment of kidney stones.

\section{METHODOLOGY}

After obtaining the approval of the Ethics Committee (Decision No. 27, meeting No. 13, dated: 12/11/2020), the data of 956 patients, who underwent $\mathrm{f}$-URS for the treatment of proximal ureteral and kidney stones between 2014 and 2020 at HSU Izmir Bozyaka Training and Research Hospital, HSU Ankara Diskapi Training and Research Hospital, and Mustafa
Kemal University Faculty of Medicine, Turkey, were retrospectively analysed in three age groups: $<60$ years (Group 1), 60-74 years (Group 2), and $\geq 75$ years (Group 3). The number, size, location and density [Hounsfield unit (HU)] of the stones and hydronephrosis degree were recorded. The patients' demographic characteristics, American Society of Anesthesiologists (ASA) score, Charlson Comorbidity Index $(\mathrm{CCl})$, use of anticoagulants, operative time (time from the insertion of the cystoscope into the urethra to the insertion of the double-J stent into the ureter), fluoroscopy duration, stone-free rates, and surgical and medical complication rates were recorded for each group. 
Table II: Postoperative results.

\begin{tabular}{|c|c|c|c|c|}
\hline Variables & $\begin{array}{l}\text { Group } 1 \\
(<60 \text { years) } \\
(n=688)\end{array}$ & $\begin{array}{l}\text { Group } 2 \\
(60-75 \text { years) } \\
(n=230)\end{array}$ & $\begin{array}{l}\text { Group } 3 \\
(\geq 75 \text { years }) \\
(n=38)\end{array}$ & p-value \\
\hline \multicolumn{5}{|l|}{$\begin{array}{l}\text { Postoperative characteristics } \\
\mathrm{n}(\%)\end{array}$} \\
\hline Stone-free rate & $561(81.5)$ & $181(78.7)$ & $28(73.7)$ & 0.354 \\
\hline Complication rate & $74(10.8)$ & $38(16.5)$ & $6(15.8)$ & 0.057 \\
\hline $\mathrm{CIRF}^{\mathrm{a}}$ rate & $31(4.5)$ & $18(7.8)$ & $2(5.3)$ & 0.152 \\
\hline Finally Success rate & $602(87.5)$ & $196(85.7)$ & $31(81.6)$ & 0.430 \\
\hline Hospitalization time, day, median (IQR) & $1(1-1)^{a}$ & $1(1-1)^{\mathrm{a}}$ & $1(1-3)^{b}$ & 0.003 \\
\hline Re-procedure requirement & & & & $0.696 *$ \\
\hline Follow-up & $84(12.2)$ & $30(13.0)$ & $8(21.1)$ & \\
\hline ESWL & $7(1.0)$ & $4(1.7)$ & $1(2.6)$ & \\
\hline Second RIRS & $49(7.1)$ & $22(9.6)$ & $2(5.3)$ & \\
\hline PCNL & $3(0.4)$ & $1(0.4)$ & 0 & \\
\hline \multicolumn{4}{|l|}{ Complication grades } & $0.143^{\wedge}$ \\
\hline Grade 1 & $54(7.8)$ & $31(13.5)$ & $5(13.2)$ & \\
\hline Postoperative hematuria & 16 & 12 & 2 & \\
\hline Fever requiring antipyretics & 38 & 18 & 3 & \\
\hline Perforation managed by without intervention & - & 1 & - & \\
\hline Grade 2 & $6(0.9)$ & $4(1.7)$ & 0 & \\
\hline Fever requiring antibiotic & 1 & 2 & - & \\
\hline Perirenal hematoma & 1 & - & - & \\
\hline Non-obstructive steinstrasse & 4 & 2 & - & \\
\hline Grade $3 a$ & $6(0.9)$ & $2(0.9)$ & 0 & \\
\hline Perirenal abscess requiring percutaneous drainage & - & 1 & & \\
\hline Perforation managed by ureteric stenting & 1 & - & - & \\
\hline Stent migration & 5 & 1 & & \\
\hline Grade $3 b$ & $6(0.9)$ & $1(0.4)$ & 0 & \\
\hline Obstructive steinstrasse & 5 & - & & \\
\hline Ureter structure & 1 & 1 & & \\
\hline Grade 4 & $1(0.1)$ & 0 & 0 & \\
\hline Urosepsis & 1 & - & - & \\
\hline Grade 5 & $1(0.1)$ & 0 & $1(2.6)$ & \\
\hline Death due to urosepsis & 1 & - & 1 & \\
\hline Medical Complications & $16(2.3)^{\mathrm{a}}$ & $41(17.8)^{b}$ & $16(42.1)^{c}$ & $<0.001$ \\
\hline Arrhythmia & 4 & 14 & 4 & \\
\hline Angina pectoris & 2 & 8 & 3 & \\
\hline Dyspepsia & 4 & 7 & 2 & \\
\hline TIA & - & 2 & 2 & \\
\hline COPD faring & 5 & 7 & 3 & \\
\hline Delirium & 1 & 3 & 2 & \\
\hline
\end{tabular}

Non-contrast computed tomography was preoperatively performed in all patients to evaluate the location, size, surface area $\left(\mathrm{mm}^{2}\right)$ and other properties of the stones. Urine culture was taken from each patient before surgery, and those with urinary tract infection were given appropriate antibiotic treatment and taken into operation once no growth was observed in their urine culture. The three groups were compared in terms of operative time, fluoroscopy duration, length of hospital stay, stone-free rate, clinically insignificant residual fragment (CIRF) and second attempt rates, and perioperative and postoperative complications according to the Clavien-Dindo classification. ${ }^{7}$

Table III: Univariate and multivariate analyses of factors associated with medical complications.

Table III: Univariate and multivariate analyses of factors associated with medical complications.
\begin{tabular}{|l|l|l|l|l|}
\hline \multicolumn{2}{|l|}{ OR (95\% Cl) } & p value & OR (95\% Cl) & p value \\
\hline BMI & $1.069(1.021-1.120)$ & 0.005 & $1.053(0.998-1.111)$ \\
\hline Age category & ref. & $<0.001$ & ref. & 0.062 \\
\hline Group 1 & $9.111(5.001-16.559)$ & $<0.001$ & $2.122(0.848-5.311)$ & $2.412(0.522-11.154)$ \\
\hline Group 2 & $30.545(13.552-68.850)$ & $<0.001$ & $<.108$ & 0.260 \\
\hline Group 3 & $3.768(2.256-6.294)$ & $<0.001$ & $0.681(0.338-1.373)$ & 0.283 \\
\hline Metabolic syndrome & $0.973(0.942-1.005)$ & 0.099 & & \\
\hline Stone length & $1.000(0.999-1.001)$ & 0.922 & & $1.004(0.992-1.016)$ \\
\hline Stone density & $1.013(1.003-1.022)$ & 0.010 & & 0.478 \\
\hline Operative time & & & \\
\hline
\end{tabular}




\begin{tabular}{|l|l|l|l|l|}
\hline ASA category & ref. & & ref. & \\
\hline ASA I & $3.494(1.646-7.414)$ & 0.001 & $1.005(0.408-2.478)$ & 0.991 \\
\hline ASA II & $13.750(6.185-30.567)$ & $<0.001$ & $1.181(0.358-3.896)$ & 0.785 \\
\hline ASA III & $77.000(19.086-310-654)$ & $<0.001$ & $1.052(0.130-8.481)$ & 0.962 \\
\hline ASA IV & $4.316(2.528-7.367)$ & $<0.001$ & $2.885(1.490-5.583)$ & 0.002 \\
\hline $\begin{array}{l}\text { Anticoagulant } \\
\text { therapy }\end{array}$ & & & \\
\hline CCI & $2.086(1.798-2.420)$ & $<0.001$ & $1.754(1.185-2.598)$ & 0.005 \\
\hline Cl: Confidence interval, BMI: Body mass index, ASA: American Society of Anesthesiologists, CCl: Charlson Comorbidity Index. \\
\hline
\end{tabular}

Perioperative complications were divided into surgical and medical groups. Surgical complications were defined as either direct procedure-related or perioperative consequences (pelvis or calyx perforation, ureteral injury, bleeding, etc.), while medical complications were accepted as those that resulted from deterioration in the current state of a patient secondary to perioperative stress, intubation, and anesthesia.

All procedures were performed with the patients in the standard lithotomy position under general anesthesia. Intravenous antibiotic prophylaxis was applied to all patients at the beginning of anesthesia according to the EAU guidelines. Operations were performed with rigid and flexible ureteroscopy. Stones were pulverised with the Holmium: YAG laser. Urethral access sheath (UAS) placement at the beginning and double-J stent placement at the end of the operation were also undertaken according to the surgeon's preference. Stone-free rate was defined as the absence of a detectable stone on ultrasonography and radiography at the first postoperative month or the absence of a stone fragment larger than $2 \mathrm{~mm}$ on computed tomography. If there were residual stones at the follow-up, a second session was planned for retrograde intrarenal surgery (RIRS) or ESWL.

Statistical analysis was performed using the Statistical Package for the Social Sciences (SPSS) version 23 for Windows. Categorical data were presented as numbers and percentages. The compliance of continuous data to normal distribution was evaluated with the Kolmogorov-Smirnov test. Continuous data did not conform to normal distribution and were given as median (interquartile range) values. Chisquare, Likelihood ratio or Exact test was used in the comparison of categorical data. The Kruskal-Wallis test was used for the comparison of non-normally distributed data. For the variables that were found to be significant, a pairwise analysis was also undertaken. The Bonferroni correction was applied in pairwise comparisons. The univariate logistic regression analysis was performed to evaluate the factors associated with medical complications, and parameters that were found to be significant at this stage were further examined using the multivariate analysis. A value of $p<0.05$ was considered statistically significant.

\section{RESULTS}

A total of 956 patients were included in the study. The characteristics of the patients and stones are given in Table I. Body mass index was significantly higher in Group 2 compared to the remaining groups $(p<0.001)$. The frequency of metabolic syndrome was found to be $8 \%, 27.8 \%$, and $71.1 \%$ in Groups 1,2 and 3 , respectively $(p<0.001)$. There was a significant difference between the groups in terms of the ASA scores. The number of patients with high ASA scores (III, IV) was significantly higher in Groups 2 and 3 compared to Group 1. A significant difference was also observed between the age groups in terms of $\mathrm{CCl}$ and anticoagulant use $(p<0.001$ for both). The intraoperative findings of the patients are shown in Table I. Only postoperative DJ stent use was significantly differ between the groups $(p=0.018)$.

The postoperative results of the patients are given in Table II. The length of hospital stay was statistically significantly higher in in Group $3(p=0.003)$. Surgical complication development was similar in Groups 1, 2 and 3 at the rates of $10.8 \%$, $16.5 \%$, and $15.8 \%$, respectively $(p=0.057)$. The classification of complications according to the Clavien-Dindo system is also shown in Table II. A significant difference was observed between the groups in relation to the medical complications $(p<0.001)$. The highest rate of medical complications was observed in Group 3 at $42.1 \%$, followed by Group 2 at $17.8 \%$, and the lowest in Group 1 at $2.3 \%(p<0.001)$.

Table III presents the results of the univariate and multivariate analyses of factors associated with medical complications. The multivariate analysis revealed that receiving anticoagulant treatment $(p=0.002)$ and having a high $\mathrm{CCl}$ ( $p=0.005$ were independent predictors of medical complication development.

\section{DISCUSSION}

It has been shown that the incidence of kidney stones has increased in the elderly population in developed countries. ${ }^{1}$ In this population, it is estimated that the stone prevalence is $19.1 \%$ among men and $9.4 \%$ among women. ${ }^{8}$ In addition, if urolithiasis is not treated in this age group, there is a higher rate of morbidity and infection, ${ }^{9}$ which has been associated with the absence of classical renal colic symptoms in certain patients delaying the diagnosis or the presence of complicated stones. ${ }^{8}$ The complications and outcomes of an operation are affected by the presence of complicated stones, aging, and increased comorbidities. In this study, the success rates were similar between all three groups, but complications were higher in the elderly patients.

The success of $f$-URS is higher than ESWL, and it has been proven that it has less morbidity than PCNL and open stone surgery. ${ }^{6}$ f-URS can be considered as a minimally invasive 
endourological approach and has become a preferred option in the treatment of kidney stones with high success and limited complication rates, especially in complicated cases such as pregnancy, obesity, coagulopathy, skeletal deformity, and kidney anomalies. ${ }^{10}$ Previous studies have emphasised that f-URS has a high stone-free and lower complication rate, but the most appropriate treatment for elderly patients with kidney stones has not yet been clearly defined. ${ }^{11}$ In a meta-analysis comparing patients that underwent f-URS and ESWL due to stone disease, the stone-free rate was reported to be higher and the rate of retreatment was lower in the f-URS group. ${ }^{12}$ Similarly, in a study evaluating patients aged over 80 years, who underwent f-URS, the stone-free rate was found to be $71.4 \% .{ }^{9}$ In the same study, operative time was found to be statistically significantly higher among the elderly patients, which was attributed to surgeons being more cautious in this patient group due to their age and comorbidities. Desai et al. found a $>90 \%$ success rate for $\mathrm{f}$-URS among patients with $1-2 \mathrm{~cm}$ stones. ${ }^{13}$ In this study, the stone-free rate was found to be high, consistent with the literature, and there was no significant difference between the groups in terms of the stone-free rate or operative time. There are many factors affecting the stone-free rate after f-URS, such as the surgeon's experience, stone size, stone location, and infundibulopelvic angle; however, patient age should also be included in these factors since there is limited fluid intake, immobilization, decreased tissue elasticity, and reduced kidney function in this population compared to relatively younger patients.

Various conditions that may affect stone formation (e.g., inactivity, dysphagia, and insufficient fluid intake) and comorbidities (e.g., hypertension, diabetes mellitus, kidney failure, and urinary tract infection) are considered to be effective in the high incidence of stones in the elderly population. ${ }^{14}$ In addition, most elderly people take drugs and vitamin supplements that can change their metabolic profile and predispose them to urinary stone disease. ${ }^{15}$ Buldu et al. reported the presence of hypertension, diabetes mellitus, or chronic obstructive pulmonary disease at a rate of $88 \%$ over the age of $65 .{ }^{16}$ Metabolic syndrome is another condition that increases with age and an effective factor in the formation of kidney stones. ${ }^{17}$

In this series, metabolic syndrome was higher among the elderly patients. Due to the deterioration in cardiopulmonary and renal function, the tolerance of elderly patients to invasive surgery may also be impaired. It is feared that the decrease in functional organ reserve with aging may trigger complications in the perioperative and postoperative period. In addition, any surgical and/or anesthesia-related complication may have a worse course in elderly patients. When $\mathrm{f}$ URS and PCNL are compared, f-URS is a more non-invasive method, and performing multiple sessions of $f-U R S$ in $>2 \mathrm{~cm}$ stones can protect the patient from the complications of PCNL, but we consider that this may increase the possibility of encountering medical complications due to anesthetic use or surgical stress. Akman et al. compared f-URS with PCNL in elderly patients and found that length of hospital stay, fluoroscopy duration, and hemoglobin decrease rate were higher in PCNL, but the operation took longer in the f-URS group. ${ }^{18}$ In the same study, the stone-free rate in a single session of medium-sized kidney stones was $82.1 \%$ and 92.8\% for the f-URS and PCNL groups, respectively, and a second procedure was required in $17.8 \%$ of patients who underwent f-URS. ${ }^{18}$ In another study, the stone-free rate was determined as $88 \%$ in a single session of $\mathrm{f}$-URS in the elderly group, and the requirement of a second procedure was observed in $13.2 \%{ }^{19}$

In the current study, the total reoperation rate was $9.3 \%$, and although the elderly group of patients had a relatively higher reoperation rate, there was no statistically significant difference between the groups. The reason for the relatively low reoperation rates may have been the small stone size. Beradinelli et al. found that the stone-free rate, operative time, UAS use, length of hospital stay, and requirement of additional procedures were not affected by patient age. ${ }^{20}$ Similar to that study, the authors found no significant difference between the groups in terms of the stone-free rate, operative time, UAS use, and additional procedures. In a previous study, lower stone-free rate and minor complications (Clavien grade I) were observed in the elderly group. ${ }^{21}$ In contrast, another study reported no difference in the stone-free and complication rates of the elderly and young groups that underwent RIRS. ${ }^{19}$

According to the literature, the overall complication rate for RIRS is $3.2 \%$ in younger patients and $11.6 \%$ in elderly patients. ${ }^{22,23}$ In a study evaluating patients over 80 years, the intraoperative complication rate was reported to be $6.4 \%$ and postoperative complications were observed in $7.7 \%$ of the cases. ${ }^{9}$. In another study, medical complications were found at a rate of $42.2 \%$ in patients over 65 years who underwent f-URS. ${ }^{24}$ Complications that occur due to non-surgical reasons (e.g., arrhythmia, angina pectoralis, dyspnea, ischemic attack, respiratory distress, and delirium) are defined as medical, and increasing age was found to be a reason for these conditions. ${ }^{24}$ The authors aimed to demonstrate the reliability of the efficacy of RIRS in patients aged over 60 years, considering that comorbid diseases and anticoagulant use are more common in this population. In light of these findings, there was no statistical difference between surgical complications in the elderly and younger patient groups, and most of the complications were classified as minor in all groups. However, medical complications were much more common in Groups 2 and 3 than in Group 1. The rate of medical complications in Group 3 was 42.1\%. Medical complications; i.e., those caused by anesthesia or comorbidities, were observed at a higher rate in the elderly patients. Multivariate analysis for medical complications found anticoagulant use and a high $\mathrm{CCl}$ as independent predictive 
factors. It is opinioned hereby that as the frequency of surgical stress increases in elderly patients, the more likely it becomes for them to develop irreversible medical complications. Therefore, before an elderly patient is taken into operation, a complete geriatric evaluation, including comorbidity scores, should be performed. ${ }^{9}$ A second situation that is as risky as surgery for this patient group is repetitive anesthesia. The solution here is to determine which patient should undergo which procedure to achieve the best results in the shortest and easiest manner as possible.

Concerning PCNL, the CROES global study reported 70 years of age to be an independent risk factor for the development and severity of complications and long-term hospital stay. ${ }^{25}$ No such age limit has yet been determined for RIRS; thus, further studies with larger case series are required.

The most important limitation of this study is its retrospective design. It is absolutely necessary to further verify this issue with larger case series and prospective and multi-center studies. The safety of surgery in elderly and young patients should also be evaluated with nomograms. This study was limited in terms of the short postoperative followup. Furthermore, there are no definitive criteria to differentiate between surgical and medical complications in the postoperative period. Lastly, since all of the patients underwent surgery under general anesthesia, the rate of medical complications may have been higher; therefore, further studies should also include patients receiving spinal anesthesia.

\section{CONCLUSION}

Due to the presence of a higher number of comorbidities and deterioration of organ functions in elderly patients, it is difficult to determine the most appropriate procedure to achieve successful results with minimal complications that they can tolerate. f-URS has been clearly demonstrated as a safe and effective alternative for the treatment of medium-sized kidney stones.

\section{ETHICAL APPROVAL:}

This study was conducted with the approval from the Ethics Committee of the Mustafa Kemal University.

\section{CONFICT OF INTEREST:}

The authors declared no conflict of interest.

\section{PATIENTS' CONSENT:}

Informed consents were obtained from all patients.

\section{AUTHORS' CONTRIBUTION:}

OK: Interpretation, drafting and final approval. IHB: Analysis, critical revision and final approval. ANK, SP: Data acquisition, conception and design. SY: Conception, design and critical revision.

TD: Final approval.

\section{REFERENCES}

1. Arampatzis S, Lindner G, Irmak F, Funk GC, Zimmermann $\mathrm{H}$, Exadaktylos AK. Geriatric urolithiasis in the emergency department: risk factors for hospitalisation and emergency management patterns of acute urolithiasis. BMC Nephrol 2012; 13:117. doi: 10.1186/1471-2369-13-117.

2. http ://www.un.org/en/devel opmen t/desa/popul ation /publi catio ns/pdf/agein g/World Popul ation Agein. United Nations, Department of Economic and Social Affairs, Population Division. (2019). World Population Ageing:2019.

3. Chatterji S, Byles J, Cutler D, Seeman T, Verdes E. Health, functioning, and disability in older adults--present status and future implications. Lancet 2015; 385(9967):563-75. doi: 10.1016/S0140-6736(14)61462-8.

4. Puppo P, Bottino P, Germinale F, Caviglia C, Ricciotti G, Giuliani L. Flexible antegrade and retrograde nephroscopy: review of 50 cases. Eur Urol 1990; 17(3):193-9. doi: 10.1159/000464036. PMID: 2351187.

5. Türk C, Knoll T, Petrik A, Sarica K, Skolarikos A, Straub M, et al. Guidelines on urolithiasis. European Association Urology Amsterdam 2020.

6. De S, Autorino R, Kim FJ, Zargar H, Laydner H, Balsamo R, et al. Percutaneous nephrolithotomy versus retrograde intrarenal surgery: A systematic review and meta-analysis. Eur Urol 2015; 67(1):125-37. doi: 10.1016/j.eururo.2014.07.003. Epub 2014 Jul 23. Erratum in: Eur Urol. 2016; 69(4):e85. PMID: 25064687.

7. Dindo D, Demartines N, Clavien PA. Classification of surgical complications: a new proposal with evaluation in a cohort of 6336 patients and results of a survey. Ann Surg 2004; 240(2):205-13. doi: 10.1097/01.sla.0000133083.54934.ae.

8. McCarthy JP, Skinner TA, Norman RW. Urolithiasis in the elderly. Can J Urol 2011; 18(3):5717-20. PMID: 21703047.

9. Emiliani E, Piccirilli A, Cepeda-Delgado M, Kanashiro AK, Mantilla D, Amaya CA, et al. Flexible ureteroscopy in extreme elderly patients (80 years of age and older) is feasible and safe. World J Urol 2020; doi: 10.1007/ s00345-020-03448-w.

10. Giusti G, Proietti S, Cindolo L, Peschechera R, Sortino G, Berardinelli $F$, et al. Is retrograde intrarenal surgery a viable treatment option for renal stones in patients with solitary kidney? World J Urol 2015; 33(3):309-14. doi: 10.1007/ s00345-014-1305-6.

11. Xu Y, Min Z, Wan SP, Nie H, Duan G. Complications of retrograde intrarenal surgery classified by the modified Clavien grading system. Urolithiasis 2018; 46(2):197-202. doi: 10.1007/s00240-017-0961-6.

12. Mi Y, Ren K, Pan H, Zhu L, Wu S, You X, et al. Flexible ureterorenoscopy (F-URS) with holmium laser versus extracorporeal shock wave lithotripsy (ESWL) for treatment of renal stone <2 cm: a meta-analysis. Urolithiasis 2016; 44(4):353-65. doi: 10.1007/s00240-015-0832-y.

13. Zeng G, Zhang T, Agrawal M, He X, Zhang W, Xiao K, et al. Super-mini percutaneous nephrolithotomy (SMP) vs retrograde intrarenal surgery for the treatment of 1-2 cm lowerpole renal calculi: an international multicentre randomised controlled trial. BJU Int 2018; 122(6):1034-040. doi: 10.1111/bju.14427.

14. Moudi E, Hosseini SR, Bijani A. Nephrolithiasis in elderly 
population; effect of demographic characteristics. J Nephropathol 2017; 6(2):63-68. doi: 10.15171/jnp.2017.11.

15. Kates M, Matlaga BR. Stones in the elderly. Curr Geri Rep 2014; s.14-18.

16. Buldu I, Tepeler A, Karatag T, Bodakci MN, Hatipoglu NK, Penbegul $\mathrm{N}$, et al. Does aging affect the outcome of percutaneous nephrolithotomy? Urolithiasis 2015; 43(2):183-7. doi: 10.1007/s00240-014-0742-4.

17. Wong $Y$, Cook P, Roderick P, Somani BK. Metabolic syndrome and kidney stone disease: A systematic review of literature. J Endourol 2016; 30(3):246-53. doi: 10.1089/ end.2015.0567.

18. Akman T, Binbay M, Ugurlu M, Kaba M, Akcay M, Yazici O, et al. Outcomes of retrograde intrarenal surgery compared with percutaneous nephrolithotomy in elderly patients with moderate-size kidney stones: A matched-pair analysis. J Endourol 2012; 26(6):625-9. doi: 10.1089/end.2011.0526.

19. Cakici MC, Sari S, Selmi V, Sandikci F, Karakoyunlu N, Ozok $U$. Is the efficacy and safety of retrograde flexible ureteroscopy in the elderly population different from non-elderly adults? Cureus 2019; 11(6):e4852. doi: 10.7759/ cureus. 4852.

20. Berardinelli F, De Francesco P, Marchioni M, Cera N, Proietti S, Hennessey $D$, et al. RIRS in the elderly: Is it feasible and safe? Int J Surg 2017; 42:147-51. doi: 10.1016/j.ijsu.2017.04.062.

21. Gokcen K, Dundar G, Bagcioglu M, Karagoz MA, Gokce G, Sarica K. Safety and efficacy of rirs in geriatric patients: A comparative evaluation on an age based manner. Urol J 2020; 17(2):129-33. doi: 10.22037/uj.v0i0.4921.

22. Prattley S, Voss J, Cheung S, Geraghty R, Jones P, Somani BK. Ureteroscopy and stone treatment in the elderly ( $\geq 70$ years): Prospective outcomes over 5 - years with a review of literature. Int Braz J Urol 2018; 44(4):750-7. doi: 10.1590/S1677-5538.IBJU.2017.0516.

23. Hu H, Lu Y, He D, Cui L, Zhang J, Zhao Z, et al. Comparison of minimally invasive percutaneous nephrolithotomy and flexible ureteroscopy for the treatment of intermediate proximal ureteral and renal stones in the elderly. Urolithiasis 2016; 44(5):427-34. doi: 10.1007/s00240-015-0854-5.

24. Aykac A, Baran O. Safety and efficacy of retrograde intrarenal surgery in geriatric patients by age groups. Int Urol Nephrol 2020; 52(12):2229-2236. doi: 10.1007/ s11255-020-02564-1.

25. Kamphuis GM, Baard J, Westendarp M, de la Rosette JJ. Lessons learned from the CROES percutaneous nephrolithotomy global study. World J Urol 2015; 33(2):223-33. doi: 10.1007/s00345-014-1367-5. 